\title{
Assessing arthritis in the context of cystic fibrosis
}

DOI:

10.1002/ppul.24290

\section{Document Version}

Accepted author manuscript

Link to publication record in Manchester Research Explorer

\section{Citation for published version (APA):}

Clarke, E. A., Watson, P., Freeston, J. E., Peckham, D. G., Jones, A. M., \& Horsley, A. (2019). Assessing arthritis in the context of cystic fibrosis. Pediatric Pulmonology. https://doi.org/10.1002/ppul.24290

\section{Published in:}

Pediatric Pulmonology

\section{Citing this paper}

Please note that where the full-text provided on Manchester Research Explorer is the Author Accepted Manuscript or Proof version this may differ from the final Published version. If citing, it is advised that you check and use the publisher's definitive version.

\section{General rights}

Copyright and moral rights for the publications made accessible in the Research Explorer are retained by the authors and/or other copyright owners and it is a condition of accessing publications that users recognise and abide by the legal requirements associated with these rights.

\section{Takedown policy}

If you believe that this document breaches copyright please refer to the University of Manchester's Takedown Procedures [http://man.ac.uk/04Y6Bo] or contact uml.scholarlycommunications@manchester.ac.uk providing relevant details, so we can investigate your claim.

\section{OPEN ACCESS}




\title{
Assessing arthritis in the context of cystic fibrosis
}

\author{
Elizabeth A. Clarke $\mathrm{MBChB}^{1,2}$ (D) | Pippa Watson $\mathrm{MBBS}^{1,3}$ | \\ Jane E. Freeston MD ${ }^{4,5}$ | Daniel G. Peckham DM ${ }^{6}$ | Andrew M. Jones MD ${ }^{1,2}$ । \\ Alex Horsley $\mathrm{PhD}^{1,2}$
}

${ }^{1}$ Division of Infection, Immunity \& Respiratory Medicine, Faculty of Biology,

Medicine and Health, University of

Manchester, Manchester, UK

2 Manchester Adult Cystic Fibrosis Centre, Wythenshawe Hospital, Manchester Foundation NHS Trust, Manchester, UK

${ }^{3}$ Rheumatology Department, Wythenshawe Hospital, Manchester Foundation NHS Trust, Manchester, UK

${ }^{4}$ NIHR Leeds Biomedical Research Centre and Department of Rheumatology, Leeds Teaching Hospitals NHS Trust, Leeds, UK

${ }^{5}$ Leeds Institute of Rheumatic and Musculoskeletal Medicine, University of Leeds, Leeds, UK

${ }^{6}$ Leeds Adult Cystic Fibrosis Unit, Leeds Teaching Hospitals NHS Trust, Leeds, UK

\section{Correspondence}

Elizabeth A. Clarke, Manchester Adult Cystic Fibrosis Centre, Wythenshawe Hospital, Manchester Foundation NHS Trust,

Manchester, M23 9LT.

Email: elizabeth.clarke@manchester.ac.uk

Funding information

Cystic Fibrosis Trust; NIHR Manchester

Biomedical Research Centre

\begin{abstract}
Inflammatory arthritis in the context of cystic fibrosis (CF) can represent a diagnostic and therapeutic challenge. Poor recognition and under-treatment of musculoskeletal conditions increases symptom burden, affects quality of life, and may lead to changes to an individual's ability to carry out activities of daily living and to exercise. A careful assessment and multidisciplinary approach is essential when considering a diagnosis of CF-associated arthritis (CFA), both in terms of identifying other treatable conditions, such as rheumatoid arthritis, and effectively addressing symptoms. In this collaboration between CF specialists and Rheumatologists, we consider joint symptoms in patients with CF, with a focus on CFA. We offer a differential diagnosis list and consider steps to assess and manage $\mathrm{CF}$ patients presenting with arthralgia including appropriate up-todate rheumatological assessment.
\end{abstract}

\section{KEYWORDS}

arthritis, cystic fibrosis (CF), inflammation

\section{1 | INTRODUCTION}

Cystic fibrosis (CF) is a multi-system disease with a large inflammatory burden. With improving survival, the relevance and impact of nonpulmonary complications has increased. The impact of CF on the musculoskeletal system includes effects on bone mineral density, muscle function, and postural changes, as well as an inflammatory arthritis known as cystic fibrosis associated arthritis (CFA). ${ }^{1}$ The impact of inflammatory arthritis in CF may be significant in terms of pain, sometimes episodic immobility, and causing difficulties with activities of daily living (see Box 1).

The potential association of an inflammatory arthritis with CF was first noted in the late $1970 \mathrm{~s}^{2,3}$ The term "CF associated arthritis" has only been used since $1987,{ }^{4}$ and has mostly been applied interchangeably with the term CF associated arthropathy. This review uses the term CF associated arthritis to mean an inflammatory arthritis, in keeping with

EC is a research fellow funded by the CF Trust as part of a Strategic Research Centre. 


\section{Box 1. What do people with CF and inflammatory arthritis say about the impact of inflammatory arthritis, and about its treatment?}

Here are comments from three of our patients:

"When my joints are bad simple things like getting dressed, doing hair, fastening buttons on clothes, shoes, etc. can be difficult. Walking my dogs, which I need to do to keep my lungs going, can be painful with my swollen knees and restrict how far I can go. Doing daily treatment and home IVs is a challenge and usually the first few days I need help to mix and sometimes administer them as my wrists/fingers are just too sore."

"Before treatment, there were days where the pain in my joints made me unable to leave the house, sometimes even bed ... now with flare ups being few and far between, I am able to go about my daily life without too much interruption."

"When the arthritis flares up it brings with it fatigue and a difficulty in motivating myself to do most daily tasks. As I have increased my Sulfasalazine these flare ups have decreased meaning ... my activity has increased ... my overall health and wellbeing also growing ... I feel better about my health and my future health than I have for a good few years."

the inflammatory signs and symptoms described in the literature. ${ }^{1,5}$ The word arthropathy is less specific and refers to any disease of the joint, not necessarily involving inflammation; we have avoided it due to its lack of specificity. Estimates of prevalence of CFA vary from $2.6 \%$ to $8.5 \%,{ }^{4}$ probably due in part to changing demographics and a variable definition. Registry data from the USA in 2016 combined the terms arthritis and arthropathy, and identified $5.8 \%$ of those over the age of 18 as having this complication. ${ }^{7}$ The UK CF Trust Registry report for 2016 gave figures separately for arthritis and arthropathy as $3 \%$ and $8.6 \%$, respectively, in those aged over 16 years. $^{8}$

Since inflammatory arthritis was first reported in CF there have been significant improvements in diagnostics for arthritis. These include serological tests such as anti-cyclic citrullinated peptide (antiCCP) antibody testing which is specific, though not sensitive, for rheumatoid arthritis, and imaging including advances in magnetic resonance imaging and ultrasound scanning. In this review, we look at the evidence for CFA diagnosis and treatment, identify some of the difficulties with changing definitions in the literature, draw comparisons with non-CF rheumatic diseases, and consider a pathway to assess and manage CF patients presenting with painful joints.

\section{2 | PRESENTATION OF CFA}

CFA is variably reported as an oligoarthritis, involving 2-4 joints, ${ }^{4}$ or polyarthritis. ${ }^{9}$ It is often remitting and relapsing, and may be flitting. ${ }^{3}$ It may lose the remitting phases with time, becoming chronic. Its association with exacerbations of chest disease is also reported variably; some authors have reported a clear link in some patients diagnosed with CFA, with joints flaring as chest disease exacerbates. ${ }^{1,9}$ Others suggest that this makes hypertrophic osteoarthropathy (HOA) more likely to be the diagnosis. ${ }^{4}$

In some cases a rash has been noted alongside the joint symptoms, most commonly a vasculitic rash, ${ }^{4,10}$ but erythema nodosum has also been described. ${ }^{9}$ The presence of a vasculitic rash, with or without joint involvement, should always prompt assessment for other organ involvement.

HOA is frequently the main differential diagnosis considered. Its main feature is a periosteal reaction which is associated with clubbing and which results in bone pain and sometimes synovitis. It is seen in a variety of lung diseases. $X$ rays show a multi-layered bony reaction, but are not sensitive as a diagnostic test. The diagnosis of HPOA in the presence of CF and joint symptoms is inconsistent in the literature. Some papers reclassify patients with CFA-like symptoms as having HOA on the basis of having oligo rather than polyarthritis, and a temporal association with infective exacerbations of chest disease, despite the absence of HOA-specific x-ray changes. ${ }^{9}$

The most clinically useful diagnosis summary from the literature is from Pertuiset et al who described CFA as "Arthropathy with clinical features of articular inflammation without articular sepsis; absence of periostitis on radiographs; absence of another cause of arthritis after evaluation." ${ }^{1}$ This makes the diagnosis one of exclusion of other rheumatic disease in a person with CF presenting with new, painful joint swelling. Of note, this also addresses the concern expressed by Botton et al that not all cases reported as CFA appeared to have been adequately assessed for other forms of inflammatory arthritis. ${ }^{5}$ Important and commonly encountered alternative diagnoses are summarized in Table 1.

\section{3 | POSSIBLE PATHOGENESIS OF CFA}

A variety of pathogenic pathways have been implicated in the development of CFA, and some parallels may be drawn with the pathogenesis of other rheumatic diseases. They may be considered in several broad categories: direct impact of CFTR (cystic fibrosis transmembrane conductance regulator) dysfunction; antigenic material and the production of associated antibodies; extra-articular inflammation driving articular inflammation; and immune system stimulation or dysregulation by microbes. Figure 1 shows a summary of some of these hypotheses.

Increased cellular stress has a number of potential mechanisms in CF including direct effects of the loss of CFTR function, and mechanisms to recycle CFTR that fails to fold correctly and cannot be inserted in the cell surface as a result. The cellular mechanisms 
TABLE 1 Differentials of CFA to consider in a patient with CF presenting with swollen joints

\begin{tabular}{|c|c|}
\hline Condition & Features \\
\hline Septic joint & $\begin{array}{l}\text { - Usually single joint } \\
\text { - Red, hot, swollen, very tender joint } \\
\text { - Systemic upset. } \\
\text { - Onset is usually very rapid, with the exception of infections with mycobacteria } \\
\text { - Refer for same day assessment as per local policy (Rheumatology or Orthopaedics) }\end{array}$ \\
\hline Rheumatoid arthritis & $\begin{array}{l}\text { - Symmetrical polyarthritis } \\
\text { - Significant early morning stiffness } \\
\text { - While useful if positive, neither rheumatoid factor nor anti-CCP are sensitive } \\
\text { - Refer to Rheumatology - early identification and treatment improves outcomes }\end{array}$ \\
\hline $\begin{array}{l}\text { Seronegative spondyloarthropathies (psoriatic arthritis, } \\
\text { ankylosing spondylitis) }\end{array}$ & $\begin{array}{l}\text { - Early morning stiffness } \\
\text { - Joint swelling often in an oligoarthritis pattern } \\
\text { - Spinal disease may exist in isolation or with peripheral disease } \\
\text { - Review for skin disease, nail pitting, and dactylitis (whole digit swelling) } \\
\text { - Any associated anterior uveitis needs prompt treatment } \\
\text { - Refer to Rheumatology } \\
\text { - Refer to Ophthalmology if eye involvement }\end{array}$ \\
\hline Inflammatory bowel disease related arthritis & $\begin{array}{l}\text { - Oligoarthritis, sometimes with spinal involvement, in the context of inflammatory } \\
\text { bowel disease } \\
\text { - Early morning stiffness } \\
\text { - Refer Rheumatology; liaise with Gastroenterology }\end{array}$ \\
\hline Henoch Schönlein purpura & $\begin{array}{l}\text { - Vasculitic rash } \\
\text { - Other complications include arthritis, arthralgia, abdominal pain with intussusception, } \\
\text { and renal involvement } \\
\text { - May appear post diarrhoeal disease or upper respiratory tract infection } \\
\text { - Assessment must include urine dipstick for blood and protein, and an albumin- } \\
\text { creatinine ratio }\end{array}$ \\
\hline Gout & $\begin{array}{l}\text { - Acute markedly painful joint inflammation } \\
\text { - Classically acute monoarthritis of first metatarsal-phalangeal joint, but may be any } \\
\text { joint and may be oligoarthritis } \\
\text { - Urate often falls in acute picture and may be normal } \\
\text { - Crystals are seen on synovial fluid microscopy }\end{array}$ \\
\hline Osteoarthritis & $\begin{array}{l}\text { - Morning stiffness of less than } 30 \text { minutes } \\
\text { - Pain worse with use } \\
\text { - Knee osteoarthritis pain may be worsened by weak quadriceps }\end{array}$ \\
\hline
\end{tabular}

which respond to this, including the unfolded protein response (UPR), can result in significant cellular stress and upregulation of proinflammatory cytokines via inflammasome activation. ${ }^{11}$ This may add to systemic inflammation including articular inflammation. A similar UPR hypothesis is proposed in ankylosing spondylitis where HLA-B27 may misfold and result in cell stress and inflammation. ${ }^{12}$

Lung inflammation is an early and sustained feature of CF. ${ }^{13}$ The systemic effect of cytokines associated with this may play a role in CFA. Tumor necrosis factor a (TNFa) and interleukin 17 (IL-17) are closely linked with other forms of inflammatory arthritis and are noted to be increased in the CF lung; anti-inflammatory interleukin 10 (IL-10) is decreased. ${ }^{14,15}$ Potential drivers of this inflammatory response becoming focused on the joints in CFA are as yet unknown.

Antigenic material and production of antibodies in response to it are noted to be important in other rheumatological conditions. In rheumatoid arthritis, anti-CCP (cyclic citrullinated peptide) antibody is produced against peptides which have been citrullinated posttranslation in inflamed lung tissue. ${ }^{16}$ This may be found prior to the 


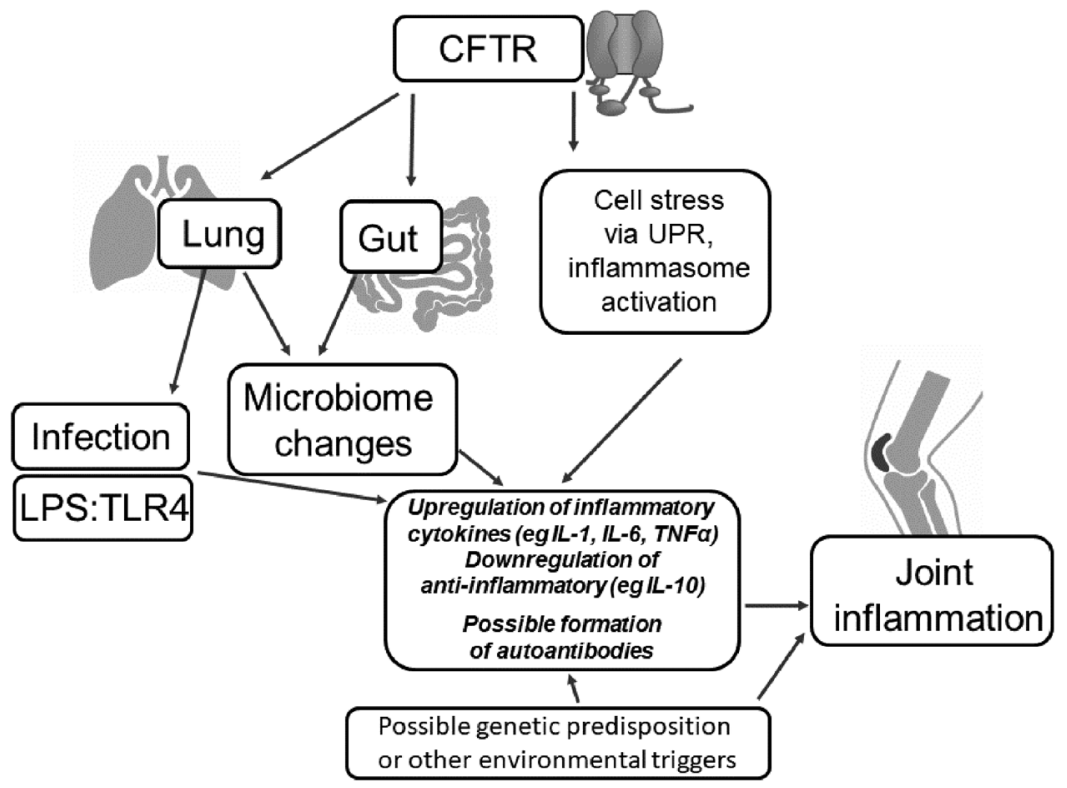

FIGURE 1 Some possible mechanisms involved in the development of inflammatory arthritis in cystic fibrosis. CFTR, cystic fibrosis transmembrane conductance regulator; UPR, unfolded protein reaction; LPS, lipopolysaccharide; TLR4, toll-like receptor 4

onset of rheumatoid arthritis symptoms, but is highly specific for the development of rheumatoid arthritis. Lung irritants such as cigarette smoke, silica, or coal dust also play a role in this, as may microbes; nonCF bronchiectasis provides a studied model for a role for bronchiectasis and chronic infection without CFTR dysfunction. ${ }^{17,18}$ Patients with non-CF bronchiectasis but without arthritis are more likely to be rheumatoid factor positive and anti-CCP positive than controls; those who are positive are more likely to go on to develop rheumatoid arthritis. Patients with rheumatoid arthritis and bronchiectasis are more frequently anti-CCP positive than patients with RA without bronchiectasis. ${ }^{18}$ Anti-CCP antibody measurement is relatively recent in clinical practice and therefore most published CFA studies do not report it. Measurement of anti-CCP has been reported in only $15 \mathrm{CF}$ patients, and was positive only in one. ${ }^{19-21}$

In systemic lupus erythematosus, antibodies are made against double stranded DNA (dsDNA). Genetic failure to clear antigenic material in the form of extracellular double stranded DNA is noted to cause a lupus-like disease including a vasculitic rash and joint inflammation. ${ }^{22}$ In CF, antigenic extracellular dsDNA exists in large volumes in airway secretions characterized by chronic infection. ${ }^{23}$ Despite this large amount of extracellular DNA, reports in CFA have not suggested a significant increase in ANA or anti-dsDNA, although a single small study reported an increase in anti-dsDNA in CF patients without reference to joint disease or vasculitis. ${ }^{24}$

Pseudomonas aeruginosa induces inflammation via the lipopolysaccharide in its cell wall. Lipopolysaccharide binds to toll like receptor 4 (TLR4) to stimulate a pro-inflammatory cytokine response from the innate immune system. ${ }^{25}$ In addition, an abnormal TLR signalling response is seen in $\mathrm{CF}^{11}$ In rheumatoid arthritis, it has been noted in the laboratory that lipopolysaccharide may also bind to collagen directly and cause apoptosis of chondrocytes and degradation of the extracellular matrix. ${ }^{26}$ Both of these mechanisms may play a role in the development of CFA.

In the gut, CFTR dysfunction is manifest in several ways. The mucus layer, especially in the small bowel, is thick and adherent, contributing to problems with small bowel overgrowth, a change in the microbiome, gut inflammation, and dysmotility. ${ }^{27}$ Gut microbiome changes are implicated in inflammatory arthritides including rheumatoid and spondyloarthropathies. Some of these changes may be driven by changes in T-cell differentiation associated with dysbiosis. ${ }^{28}$ Gut inflammation is linked most strongly with seronegative spondyloarthropathies, and $30 \%$ of patients with inflammatory bowel disease have an associated arthropathy. ${ }^{29}$ It is therefore possible that gut dysfunction, microbiome changes, and inflammation play a role in CFA in a similar manner.

\section{4 | INVESTIGATIONS IN CFA}

The scope and specificity of both serological and imaging investigations available has changed considerably over the last 30 years, and there is a paucity of evidence for the interpretation of results such as a raised rheumatoid factor or anti-nuclear antibodies in the $\mathrm{CF}$ population. We have summarized in Box 2 our current suggestions regarding assessment of a patient with $\mathrm{CF}$ and joint swelling.

Inflammatory markers are frequently raised, but often only marginally. ${ }^{3,9}$ ANA (anti-nuclear antibody) was reported as positive in 7 of 68 patients $(10 \%)^{2,3,8,11-14,30}$ but information on titre and pattern was frequently missing. ANA may be positive in healthy individuals, the incidence rising with age and with some geographical variation; titre and pattern information is therefore vital to interpret results. Measurement of rheumatoid factor has been reported for 60 patients 


\section{Box 2. Assessment of a patient with CF and joint swelling}

- A whole patient approach must be taken, considering the joints in the overall picture. This must include skin and kidneys (vasculitis, Henoch Schönlein Purpura), bowel disease (inflammatory bowel disease-related joint disease, reactive arthritis) and sexual health (reactive arthritis) as well as chest disease. An examination should also include other joints in addition to the presenting joints. Blood pressure should be checked and urine examined for proteinuria and haematuria.

- Blood tests should include inflammatory markers, urate, ANA (anti-nuclear antibodies), rheumatoid factor, and anti-CCP (cyclic citrullinated peptide) antibodies. ANCA should be included if there is a vasculitic rash. While strongly positive immunology is suggestive of specific conditions, negative immunology results do not rule out inflammatory arthritis. Urate may drop acutely in a flare of gout.

- Imaging should be considered and discussed with rheumatology. Plain x-ray will identify HOA, and damage from longstanding inflammatory arthritis. Ultrasound and MRI show inflammation prior to this causing bone destruction.

- A coordinated multi-disciplinary team assessment should include prompt referral to physiotherapy to minimise deterioration in activity and respiratory health. There may be a need to alter the respiratory physiotherapy regime if the patient is unable to exercise at their normal level. Following a flare, physiotherapy can help with getting joints moving again after they have been painful, and ensuring that muscle bulk is preserved as much as possible. A review by a rheumatology occupational therapist may be vital in preserving independence with activities of daily living during flares. with CFA, with a positive result in 8; however, titres as low as 1/10 were recorded as positive. ${ }^{6}$ Of 15 anti-CCP results reported, 1 was positive. ${ }^{19-21}$ Synovial fluid results were reported in two studies; clear paucicellular synovial fluid with negative microbial and crystal investigations were described in a total of six patients. ${ }^{1,10}$

Imaging techniques have also changed over this time period. Plain film radiography remains a useful investigation for identifying erosive disease. Whether CFA is an erosive disease or not remains a little controversial, as identified by Pertuiset et al, with regards to whether cases of erosive arthritis reported in people with CF represent erosive rheumatoid arthritis, or CFA. ${ }^{1}$ Some of the patients with erosive disease were seropositive for rheumatoid factor, although in most papers it is not possible to tell whether the patients with erosions were the same as the patients with positive rheumatoid factor. ${ }^{6}$ Technetium scans were reported in one study in which they were used instead of $x$ rays for HOA diagnosis, due to better sensitivity for this differential of CFA. $^{31}$ Sensitive imaging modalities such as magnetic resonance imaging and ultrasound are now more readily available to assess joint disease, with a proven ability to image inflammation in joints. ${ }^{32} \mathrm{MRI}$ and ultrasound use in CFA, however, has only been reported in one study, concluding that ultrasound may be the more feasible of the two to image the inflammation seen in CFA. ${ }^{21}$ See Figure 2 for an example of the images seen using ultrasound in inflammatory arthritis. The evidence for the use of these increasingly available, non-invasive assessments must therefore be primarily extrapolated from their use in other rheumatic disease.

\section{5 | EVIDENCE FOR TREATMENT}

There are no well-conducted clinical trials of either non-steroidals ${ }^{33}$ or disease modifying anti-rheumatic drugs ${ }^{34}$ (DMARDs, conventional, such as methotrexate, or biological, such as anti-TNFa drugs) in CFA. Perhaps given the lack of a formal definition of CFA and variably reported signs, this is unsurprising. The case report data available has two major caveats: firstly that some of them refer to medications now rarely used in rheumatic disease, such as gold ${ }^{6}$, and secondly that some of these patients had possibly not been adequately assessed for other causes of their joint disease. From the point of view of reviewing the

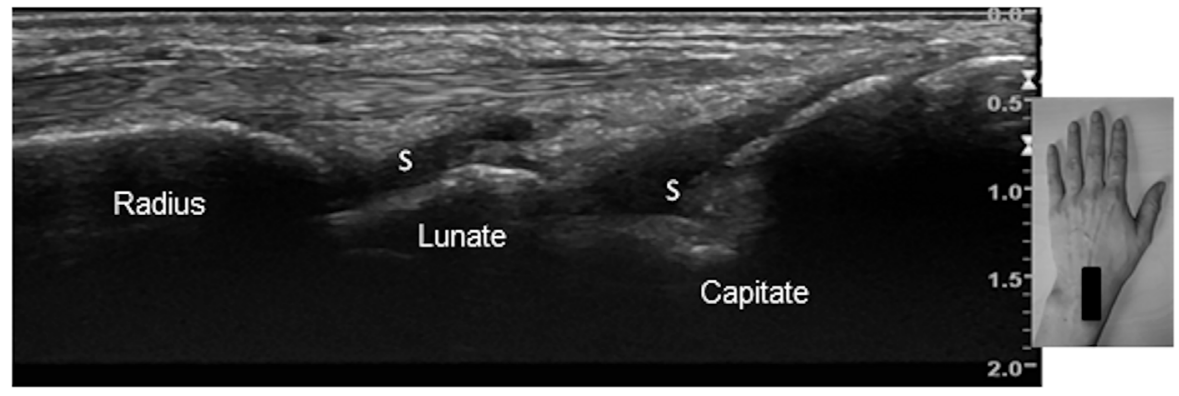

FIGURE 2 Greyscale ultrasound image of a wrist in showing the right radiocarpal joint (radius, lunate, capitate are labelled) with synovial thickening during an acute flare of cystic fibrosis associated arthritis. Thickened synovium (S) is seen extending out of the joint space as hypoechoic areas which are noncompressible. Probe position is shown in the picture on the right 
safety of newer, biological, DMARDs for patients with CF, information may also be drawn from reports of patients with CF receiving them for non-rheumatological indications.

Dixey et $\mathrm{al}^{9}$ reported that 11 of 12 patients improved acutely with non-steroidals, though episodic joint symptoms continued in 8/12 patients. Corticosteroids and non-steroidals may both be used symptomatically but their potential side effects must be taken into account. Alongside other side effects, including increased insulin resistance and immunosuppression, proximal myopathy due to long term corticosteroid use may worsen joint pains in the longer-term. Non-steroidals carry some risks for patients with CF that may be higher than in the general population: a high prevalence of gastrooesophageal reflux disease may predispose to gastrointestinal side effects. $^{35}$

In four patients in whom episodic arthritis progressed to persistent disease, treatments including NSAIDs, gold, hydroxychloroquine and prednisolone were used; specific case outcomes were not reported. ${ }^{6}$ Outside of the literature, hydroxychloroquine has been used for CFA, but all evidence for its use as monotherapy is extrapolated from its use in other rheumatic disease. A case of seropositive erosive inflammatory arthritis in CF is the only report describing use of hydroxychloroquine without other DMARD therapy; no information regarding effectiveness was given and this may represent a case of rheumatoid arthritis in CF rather than CFA. ${ }^{6}$ Failure of triple therapy (oral methotrexate $25 \mathrm{mg}$ weekly, sulfasalazine $1.5 \mathrm{~g} \mathrm{BD}$, hydroxychloroquine $200 \mathrm{mg} \mathrm{BD}$ ) and oral prednisolone for 3 months in the case of a patient with recurrent bilateral knee synovitis preceded successful treatment with anti-TNFa (tumor necrosis factor) therapy (etanercept) and methotrexate. ${ }^{19}$ His joints improved and he did not suffer from an increased infection rate during a one year follow up period; prednisolone was tapered and stopped. The authors note that his quality of life improved significantly. No other cause of rheumatological disease was found, there was no family history of note, and serological investigations were negative.

A case report of rheumatoid arthritis also described anti-TNFa therapy (infliximab) being used safely in a patient with CF. ${ }^{36}$ Some evidence on safety of biologics in CF, if not efficacy in CFA, may be drawn from their use in other extra-pulmonary inflammatory conditions in CF: Infliximab use has been reported in two patients with CF, Crohn's disease and chronic Pseudomonas aeruginosa infection. ${ }^{37,38}$ Both patients gained weight, and the Crohn's disease was controlled. Both also reported stable lung function at 2 years on therapy, and no significant infective exacerbations during this time. No published cases report worsening of lung disease, but publication bias may play a role here.

Making treatment recommendations with an insufficient evidence base is difficult, but given the situation at present, our own current departmental recommendations for treatment are outlined in Box 3. While evidence for treating CFA is lacking, good evidence for treating other types of inflammatory arthritis is abundant and includes strong evidence that prompt treatment improves outcomes. ${ }^{39,40}$

Long term outcomes for patients diagnosed with CFA have not been reported prospectively; cases that progress from relapsing-remitting

\section{Box 3. Treatment of patients with CFA (at present defined as joint pain with objective evidence of joint inflammation in the context of CF after excluding other comorbid rheumatological disease)}

Combined Rheumatology and CF review, and ongoing multidisciplinary team input are key. This should include considering input from musculoskeletal physiotherapy and occupational therapy.

Acute isolated episodes:

- Short term non-steroidals are first line for symptom relief; if contraindicated, other simple analgesia should be tried.

- Non-medical therapy including short-term intermittent splinting may reduce pain.

- Steroids (intra-articular if a single joint affected and no concurrent infection, otherwise oral or intramuscular) may be useful if the episode is not settling.

Chronic or recurrent episodes:

- Long term treatment with a DMARD (disease modifying anti-rheumatic drug) should be considered, but should not be started without review by Rheumatology and ongoing input.

- In the absence of good evidence, hydroxychloroquine is a reasonable first line choice. No ongoing blood monitoring is required for this, but eye screening is. Patient information leaflets should be given; good resources include USA-based Rheum Info (rheuminfo.com) and the UK-based Versus Arthritis (versusarthritis.org). Locally, sulfasalazine is used as a second line option if considered appropriate. This requires counselling, blood monitoring and careful up-titration.

- Evidence regarding the safety of both conventional (eg, sulfasalazine, methotrexate) and biologic DMARDs in CF is growing, but remains limited: ongoing input from Rheumatology is vital.

to chronic $\left(50 \%\right.$ in one series $\left.{ }^{6}\right)$ must be re-evaluated for other rheumatic disease and have treatment decisions reassessed.

\section{6 | CONCLUSIONS}

CFA is a condition that causes pain and impacts quality of life, and one for which our knowledge base has significant gaps. Discussion with people with cystic fibrosis and inflammatory arthritis (Box 1) highlights some of the difficulties of living with this combination, as well as the 
potential for improvement with assessment and treatment. We present suggestions for careful assessment of patients, partially extrapolating from work in other areas of rheumatic disease, in order to offer patients the best care currently possible and to ensure that alternate diagnoses are not overlooked. Management should draw on the expertise of Rheumatologists who are extremely familiar with the diagnosis and treatment of inflammatory arthritis; multi-disciplinary input from CF and Rheumatology teams is essential for good patient care. In future work, particular consideration must go to developing a robust definition of CFA to allow the development of appropriate diagnostic pathways and trials to evaluate treatments in this condition.

\section{ACKNOWLEDGMENTS}

EC is supported by the CF trust. AH is supported by the NIHR Manchester Biomedical Research Centre.

\section{ORCID}

Elizabeth A. Clarke iD http://orcid.org/0000-0002-6703-6281

\section{REFERENCES}

1. Pertuiset E, Menkes CJ, Lenoir G, Jehanne M, Douchain F, Guillot M. Cystic fibrosis arthritis. A report of five cases. $\mathrm{Br} J$ Rheumatol. 1992;31:535-538.

2. Mathieu JP, Stack BH, Dick WC, Buchanan WW. Pulmonary infection and rheumatoid arthritis. Br J Dis Chest. 1978;72: 57-61.

3. Newman AJ, Ansell BM. Episodic arthritis in children with cystic fibrosis. J Pediatr. 1979;94: 594-596.

4. Bourke S, Rooney M, Fitzgerald M, Bresnihan B. Episodic arthropathy in adult cystic fibrosis. Q J Med. 1987;64: 651-659.

5. Botton E, Saraux A, Laselve H, Jousse S, Le Goff P. Musculoskeletal manifestations in cystic fibrosis. Joint Bone Spine 2003;70:327-335.

6. Rush PJ, Shore A, Coblentz C, Wilmot D, Corey M, Levison H. The musculoskeletal manifestations of cystic fibrosis. Semin Arthritis Rheum. 1986;15:213-225.

7. Marshall B, Faro A, Elbert A, et al. Annual Data Report 2016. Cystic Fibrosis Foundation Patient Registry. 2016;2016:1-94.

8. Jeffery A, Charman S, Cosgriff R, Carr S. UK Cystic Fibrosis Registry Annual Data Report 2016

9. Dixey, J, Redington AN, Butler RC, et al. The arthropathy of cystic fibrosis. Ann Rheum Dis 1988;47:218-223.

10. Wulffraat NM, de Graeff-Meeder ER, Rijkers GT, van der Laag H, Kuis W. Prevalence of circulating immune complexes in patients with cystic fibrosis and arthritis. J Pediatr. 1994;125:374-378.

11. Cohen-Cymberknoh M, Kerem E, Ferkol T, Elizur A. Airway inflammation in cystic fibrosis: molecular mechanisms and clinical implications. Thorax. 2013;68: 1157-1162.

12. McHugh K, Bowness P. The link between HLA-B27 and SpA?new ideas on an old problem. Rheumatology. 2012;51: 1529-1539.

13. Cantin AM, Hartl D, Konstan MW, Chmiel JF. Inflammation in cystic fibrosis lung disease: pathogenesis and therapy. J Cyst Fibros. 2015;14: 419-430.

14. Courtney JM, Ennis M, Elborn JS. Cytokines and inflammatory mediators in cystic fibrosis. J Cyst Fibros. 2004;3: 223-231.

15. Tan H-L, Regamey N, Brown S, Bush A, Lloyd CM, Davies JC. The Th17 pathway in cystic fibrosis lung disease. Am J Resp Crit Care Med. 2011;184: 252-258.
16. Catrina Al, Ytterberg AJ, Reynisdottir G, Malmström V, Klareskog L. Lungs, joints and immunity against citrullinated proteins in rheumatoid arthritis. Nat Rev Rheumat. 2014;10: 645-653.

17. Perry E, Kelly C, Eggleton P, De Soyza A, Hutchinson D. The lung in ACPA-positive rheumatoid arthritis: an initiating site of injury? Rheumatology. 2014;53: 1940-1950.

18. Quirke A-M, Perry E, Cartwright A, et al. Bronchiectasis is a model for chronic bacterial infection inducing autoimmunity in rheumatoid arthritis. Arthritis Rheumatol. 2015;67: 2335-2342.

19. Adelsten $T$, Rasmussen $N$, Katzenstein $T$, Nielsen $C$. Safe and effective tumour necrosis factor- $a$ inhibitor (etanercept) treatment of chronic episodic arthritis in a patient with cystic fibrosis. Scand J Rheumatol. 2016;45: 330-331.

20. Schnell A, Imran M, Crosser M, Maz M. Patterns of arthropathy in patients with cystic fibrosis - ACR meeting abstracts. Arthritis Rheumatol. 2015;67.

21. Fitch G, Williams K, Freeston JE, et al. Ultrasound and magnetic resonance imaging assessment of joint disease in symptomatic patients with cystic fibrosis arthropathy. J Cyst Fibr. 2016;15: e35-e40.

22. Özçakar ZB, Foster J, Diaz-Horta O, et al. DNASE1L3 mutations in hypocomplementemic urticarial vasculitis syndrome. Arthritis Rheumat. 2013;65: 2183-2189.

23. Nichols DP, Chmiel JF. Inflammation and its genesis in cystic fibrosis. Pediatr Pulmonol. 2015;50:S39-S56.

24. Schiotz PO, Egeskjold EM, Hoiby N, Permin H. Autoantibodies in serum and sputum from patients with cystic fibrosis. Acta Pathol Microbiol Scand. 1979;87: 319-324.

25. Rowe SM, Miller S, Sorscher EJ. Cystic fibrosis. N Engl J Med. 2005;352: 1992-2001.

26. Lorenz W, Buhrmann C, Mobasheri A, Lueders C, Shakibaei M. Bacterial lipopolysaccharides form procollagen-endotoxin complexes that trigger cartilage inflammation and degeneration: implications for the development of rheumatoid arthritis. Arthritis Res Ther. 2013;15: R111.

27. Dorsey J, Gonska T. Bacterial overgrowth, dysbiosis, inflammation, and dysmotility in the Cystic Fibrosis intestine. J Cyst Fibr. 2017;16: S14-S23.

28. Jethwa $\mathrm{H}, \mathrm{Abraham} \mathrm{S}$. The evidence for microbiome manipulation in inflammatory arthritis. Rheumatology 2016;56: kew374.

29. Arvikar SL, Fisher MC. Inflammatory bowel disease associated arthropathy. Curr Rev Musculoskelet Med. 2011;4: 123-131.

30. Lawrence JM, 3rd, Moore TL, Madson KL, Rejent AJ, Osborn TG. Arthropathies of cystic fibrosis: case reports and review of the literature. J Rheumatol. 1993;38:12-15.

31. Massie R, Towns S, Bernard E, Chaitow J, Howman-giles R, Van Asperen PP. The musculoskeletal complications of cystic fibrosis. J Paediatr Child Health. 1998;34: 467-470.

32. Colebatch AN, Edwards CJ, Østergaard M, et al. EULAR recommendations for the use of imaging of the joints in the clinical management of rheumatoid arthritis. Ann Rheum Dis. 2013;72: 804-814.

33. Thornton J, Rangaraj S. Anti-inflammatory drugs and analgesics for managing symptoms in people with cystic fibrosis-related arthritis. Cochrane Database Syst Rev. 2016; Art. No.: CD006838. https://doi. org/10.1002/14651858.CD006838.pub4

34. Thornton J, Rangaraj S. Disease modifying anti-rheumatic drugs in people with cystic fibrosis-related arthritis. Cochrane Database Syst Rev. 2012; Art. No.: CD007336. https://doi.org/10.1002/14651858. CD007336.pub3

35. Maqbool A, Pauwels A. Cystic Fibrosis and gastroesophageal reflux disease. J Cyst Fibros. 2017;16:S2-S13.

36. Casserly B, Donat W. Stabilization of lung function and clinical symptoms in a patient with cystic fibrosis (CF) after institution of infliximab: a monoclonal antibody that binds tumor necrosis factor alpha. Lung. 2009;187: 149-152. 
37. Gibson DJ, Gallagher CG, Doherty GA. Infliximab is safe and induces sustained remission with complete mucosal healing in Crohn's disease in a patient with pan resistant pseudomonas cystic fibrosis: a case report. J Crohns Colitis. 2014;8: 1561-1562.

38. Vincenzi F, Bizzarri B, Ghiselli A, de' Angelis N, Fornaroli F, de' Angelis GL. Cystic fibrosis and Crohn's disease: successful treatment and long term remission with infliximab. World J Gastroenterol. 2010;16:1924.

39. Grigor C, Capell H, Stirling A, et al. Effect of a treatment strategy of tight control for rheumatoid arthritis (the TICORA study): a single-blind randomised controlled trial. Lancet. 2004;364: 263-269.
40. Coates LC, Moverley AR, McParland L, et al. Effect of tight control of inflammation in early psoriatic arthritis (TICOPA): a UK multicentre, open-label, randomised controlled trial. Lancet. 2015;386: 2489-2498.

How to cite this article: Clarke EA, Watson P, Freeston JE, Peckham DG, Jones AM, Horsley A. Assessing arthritis in the context of cystic fibrosis. Pediatric Pulmonology. 2019;1-8. https://doi.org/10.1002/ppul.24290 